\title{
Development of the International Network of Agencies for Health Technology Assessment
}

\author{
David Hailey \\ Institute of Health Economics and University of Queensland
}

Objectives: To describe the development of the International Network of Agencies for Health Technology Assessment (INAHTA) and its activities.

Methods: Review of literature material and other documents produced by or relating to INAHTA.

Results: INAHTA includes organizations that provide health technology assessment (HTA) advice to governments and receive most of their funding from public sources. In early 2009 , there were forty-six members from twenty-seven countries, including both national and regional agencies. Interaction with other organizations includes links to Health Technology Assessment International (HTAi), the European Union Network for Health Technology Assessment (EUnetHTA), PAHO (the Pan American Health Organization, and the World Health Organization (WHO). An important feature of INAHTA is the routine interaction of its members with public sector decision makers. Output from the network has included guidelines and frameworks on HTA, reports of surveys, and joint projects.

Conclusions: INAHTA has developed as a global point of contact and information for those with interests in HTA.

Keywords: Health technology assessment, International agencies, Collaborations, Information services

The formation of the International Network of Agencies for Health Technology Assessment (INAHTA) was a step in the evolution of health technology assessment (HTA) as it became associated with increased international cooperation. Following the initial work on HTA in the United States and Sweden, several other countries established programs at national and regional levels, which often found they were dealing with similar assessment topics and issues. There was increasing perception that cooperation between agencies would reduce unnecessary duplication of activities, enable a more efficient sharing of expertise and information, and advance the field of HTA (4).

\section{THE FORMATION OF INAHTA}

Exchange of information about HTA agencies' activities, and the development of a more systematic approach to communication and cooperation were explored in seminars involving agency representatives who attended the 1992 and 1993
Annual Meetings of the International Society of Technology Assessment in Health Care (ISTAHC). INAHTA was subsequently established at a meeting in Paris in 1993, hosted by the national French agency Agence Nationale pour le Développement de l'Evaluation Médicale (ANDEM) (2). There were thirteen founding member agencies from Australia, Canada, France, the Netherlands, Spain, Sweden, Switzerland, the United Kingdom, and the United States.

The structure and activities of INAHTA were framed at the Paris meeting and at the 1994 meeting of the network, which followed the ISTAHC Annual Meeting in Baltimore. Membership would be open to organizations that operated ongoing HTA programs, produced regular HTA reports, provided advice to governments, and received at least 50 percent of their operating funds from public sources. Member agencies would provide funds to establish a small secretariat, located at the Canadian Coordinating Office for Health Technology Assessment. Administration of the network would be steered by a three-person executive board. As a 


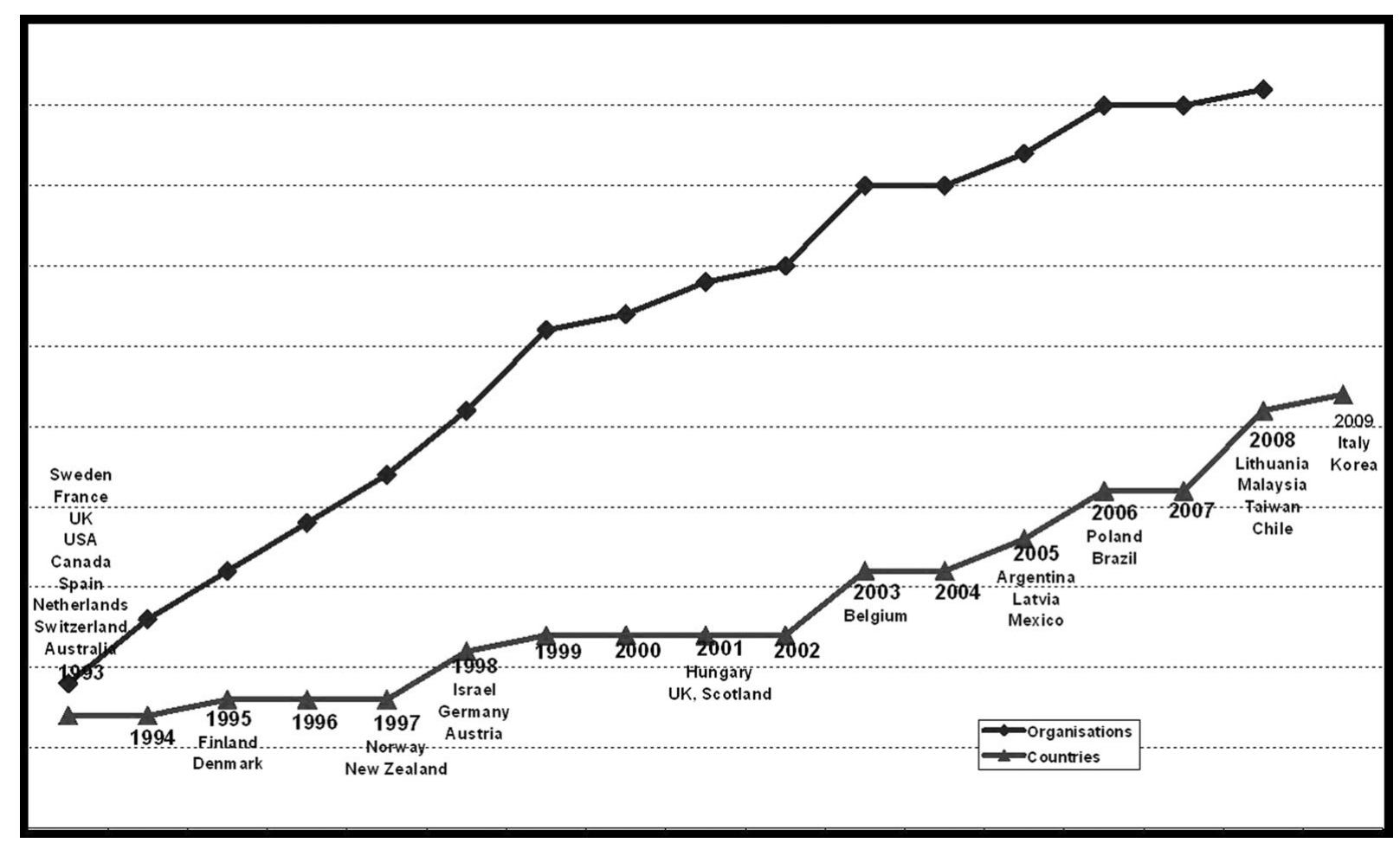

Figure 1. Entry of organizations and countries to the International Network of Agencies for Health Technology Assessment (INAHTA).

Table 1. INAHTA Members: Number of Agencies by Country, 2009

\begin{tabular}{llll}
\hline Argentina & 1 & Lithuania & 1 \\
Australia & 3 & Malaysia & 1 \\
Austria & 1 & Mexico & 1 \\
Belgium & 1 & Netherlands & 3 \\
Brazil & 1 & New Zealand & 1 \\
Canada & 4 & Norway & 1 \\
Chile & 1 & Poland & 1 \\
Denmark & 2 & Spain & 6 \\
France & 2 & Sweden & 1 \\
Finland & 1 & Switzerland & 1 \\
Germany & 2 & Taiwan & 1 \\
Israel & 1 & UK & 4 \\
Italy & 1 & USA & 2 \\
Korea & 1 & & \\
\hline
\end{tabular}

first collaborative activity, a data base of abstracts of agencies' publications would be prepared.

\section{Growth and Development of the Network}

Membership of the network has grown steadily over the years and by April 2009 there were forty-six members from twentyseven countries (Figure 1; Table 1). Membership continues to include both national and regional HTA agencies. A few agencies have ceased membership because of abolition, funding difficulties, or changes in mandate, and others have had changes to their titles or administrative arrangements.
In 1996, the INAHTA secretariat moved to the Swedish Council on Technology Assessment in Health Care (SBU), which has continued to carry this responsibility. The size of the Executive Board was increased to assist with administration of the larger group of agencies.

Communication approaches for INAHTA evolved with development of a Web site (http://www.inahta.org) and an email-based listserv to provide a forum for discussion and information exchange between member agencies.

\section{Activities of the network}

The data base of abstracts evolved into the HTA Database, which is managed by the Centre for Reviews and Dissemination at the University of York in collaboration with INAHTA. By mid-2008 the data base included 3690 reports and 949 projects. Information on assessments by members is also provided through standardized one-page abstracts (INAHTA Briefs) of their recent HTA reports, which are available on the Web site.

Output from the network has included guidelines and frameworks on HTA, reports of surveys, and joint projects. INAHTA develops such products and its communication approaches through working groups made up of persons from member agencies. The current working groups cover External Partnership, Internal Communication, Impact of HTA, Quality Assurance, Education and Training, Ethical Issues, and Membership Criteria. 
Reference documents, providing guidance on various aspects of HTA, include a checklist for HTA reports, an HTA Glossary, a report on handling ethical issues in HTA, and a Toolbox for Health Care Decision Makers (a collection of products from members of INAHTA). Surveys within INAHTA have provided information on practice and opinions from member agencies. Topics have included educational and training activities, impact of HTA on policy, and involvement of consumers in HTA.

Joint projects between INAHTA agencies on assessment of specific technologies began early in the life of the network with a major review on bone density measurement and the treatment of osteoporosis (3). This was followed by reports on prostate cancer screening, telemedicine, and preoperative evaluation in elective surgery, and more recently by appraisal of positron emission tomography (1).

\section{Interaction With Other Organizations}

Annual face to face meetings of the INAHTA membership have been held immediately before or after the Annual Meetings of ISTAHC, and now Health Technology Assessment International (HTAi). In 2008, INAHTA and HTAi entered into a Memorandum of Understanding (MOU), agreeing to cooperate in promotion of HTA, organisation and governance, scheduling of annual meetings, communication, and joint activities. The MOU essentially outlines activities that have been in place for some time.

There have also been long-standing links between INAHTA and assessment networks supported by the European Union. There was an open and constructive relationship with the EUR-ASSESS project with the two networks having considerable cross-membership and complementary activities (2). INAHTA and the current European network, EUnetHTA, have been collaborative partners since January 2006. The partnership will allow greater access to draft reports, language translation, and peer reviews, and provide the opportunity for joint projects.

INAHTA became a collaborating partner with WHO in May 2007, and the network is expecting to contribute to mentoring and development of HTA in countries and regions that have limited HTA capability. This seems likely to include links to relevant World Bank activities. INAHTA has also cooperated with PAHO on promotion of HTA in Latin American countries and with the Guidelines International Network in the development of evidence tables.

\section{Challenges}

Resources available to INAHTA are quite limited. It has a modest budget, supported by membership fees, much of which is committed to support for the secretariat and annual meetings. Substantial increases in fees would present difficulties for several member agencies. Projects that INAHTA undertakes rely heavily on the input from individual agencies to activities of the working groups. There are clearly limits to the time and resources that members can offer. Their main responsibilities lie in providing HTA in their own countries. Relatively limited resources may be appropriate for a network of this nature, but inevitably there are constraints on what INAHTA can undertake, particularly on more complex projects.

\section{Concluding Comments}

Although its resources are modest, INAHTA has built up a solid record of achievements. It has been effective in improving communication between agencies and in developing as a source of expertise in HTA. An important feature is the routine interaction of its members with public sector decision makers. INAHTA has facilitated collaboration between HTA agencies, typically through its working groups, at a level that did not exist before establishment of the network. Projects, and participating agencies, have benefited from the exchange of perspectives and expertise on various topics. INAHTA has also been associated with collaborative projects outside its immediate work program, such as a recent overview of rapid HTAs (5).

As suggested in a previous review (2), INAHTA's success is indicated by its growing membership, with HTA agencies prepared to invest some of their typically small discretionary budgets in membership fees. Members continue to see value from their participation in the network, although the extent of satisfaction will vary with progress made in different areas and with the visions of individual agencies.

INAHTA has developed into a global point of contact for agencies and others with interests in HTA. Interaction with other networks may extend the scope of its future activities.

\section{ACKNOWLEDGEMENT}

I am grateful to Oksana Selezneva, INAHTA Secretariat, $\mathrm{SBU}$, for providing the diagram used in Figure 1.

\section{CONTACT INFORMATION}

David Hailey, MSc, PhD (dhailey@ozemail.com.au), Visiting Fellow, Centre for Online Health, University of Queensland, Foundation Building, Royal Children's Herston, Queensland 4029, Australia; Senior Advisor, Institute of Health Economics, \#1200, 10405 Jasper Avenue, Edmonton, Alberta T5J 3N4, Canada

\section{REFERENCES}

1. Adams EJ, Almazán C, Mørland B, et al. Joint project of the International Network of Agencies for Health Technology Assessment-Part 2: Managing the diffusion of positron emission tomography with health technology assessment. Int $J$ Technol Assess Health Care. 2006;22:149-154. 
2. Hailey D, Menon D. A short history of INAHTA. Int J Technol Assess Health Care. 1999;15:235-241.

3. Hailey D, Sampietro-Colom L, Marshall D, et al. The effectiveness of bone density measurement and associated treatments for prevention of fractures, An international collaborative review. Int J Technol Assess Health Care. 1998;14:237254.
4. Menon D, Marshall D. The internationalization of health technology assessment. Int J Technol Assess Health Care. 1996;12:45-51.

5. Watt A, Cameron A, Sturm L, et al. Rapid reviews versus full systematic reviews: An inventory of current methods and practice in health technology assessment. Int J Technol Assess Health Care. 2008;24:133-139. 